University of Nebraska - Lincoln

DigitalCommons@University of Nebraska - Lincoln

Faculty Publications, Department of Psychology

Psychology, Department of

2009

\title{
Low-Level Lead Exposure and Contingency-Based Responding in Preschoolers: An Exploratory Study
}

Melanie McDiarmid Nelson

University of Oklahoma Health Sciences Center, melanie-nelson@ouhsc.edu

Kimberly A. Espy

University of Nebraska-Lincoln, kespy2@unl.edu

Follow this and additional works at: https://digitalcommons.unl.edu/psychfacpub

Nelson, Melanie McDiarmid and Espy, Kimberly A., "Low-Level Lead Exposure and Contingency-Based Responding in Preschoolers: An Exploratory Study" (2009). Faculty Publications, Department of Psychology. 602.

https://digitalcommons.unl.edu/psychfacpub/602

This Article is brought to you for free and open access by the Psychology, Department of at DigitalCommons@University of Nebraska - Lincoln. It has been accepted for inclusion in Faculty Publications, Department of Psychology by an authorized administrator of DigitalCommons@University of Nebraska - Lincoln. 
Published in Developmental Neuropsychology 34:4 (2009), pp. 494-506; doi:

$10.1080 / 87565640902964508$

Copyright (c) 2009 Taylor \& Francis Group, LLC. Used by permission.

\title{
Low-Level Lead Exposure and Contingency- Based Responding in Preschoolers: An Exploratory Study
}

\author{
Melanie McDiarmid Nelson \\ Department of Pediatrics, Section of Developmental and Behavioral Pediatrics, \\ University of Oklahoma Health Sciences Center, Oklahoma City, Oklahoma \\ Kimberly Andrews Espy \\ Office of Research \& Department of Psychology, \\ University of Nebraska-Lincoln, Lincoln, Nebraska \\ Corresponding author - Melanie McDiarmid Nelson, University of Oklahoma Health Sciences \\ Center-Pediatrics, Child Study Center, 1100 NE 13th Street, Oklahoma City, OK 73117; \\ email melanie-nelson@ouhsc.edu
}

\begin{abstract}
Two reversal paradigm tasks (spatial reversal and spatial reversal with irrelevant color cues) originally designed to assess contingency-based responding in primates were adapted for use with 139 preschool children with a mean peak blood lead level (BLL) of $4.2 \mu \mathrm{g} / \mathrm{dl}(S D=2.2)$. Sixty-nine children with BLL $\geq 5 \mu \mathrm{g} / \mathrm{dl}$ and 70 children with BLL of $<5 \mu \mathrm{g} / \mathrm{dl}$ were included. Results indicated that preschool children with low-level lead exposure take longer to learn associations than preschool children with very low levels of lead exposure, and this difference cannot be attributed to increased distractibility or perseverative responding. These results support the use of these measures to assess specific cognitive functions in preschool children.
\end{abstract}

\section{Introduction}

Although humans have used lead $(\mathrm{Pb})$ in many applications for centuries, the demonstrated link between lead exposure (LE) and poor cognitive and health outcomes only recently has prompted government agencies to regulate and reduce the amount of environmental lead primarily through prohibiting lead in paint and gasoline. Concommitantly, the Centers for Disease Control and Prevention, which sets national guidelines for acceptable blood lead levels (BLLs), reduced the defined critical level from $40 \mu \mathrm{g} / \mathrm{dl}$ in 1970 to the current (1991) recommendation of $10 \mu \mathrm{g} / \mathrm{dl}$. As a result, mean population lead levels, measured by micrograms of lead per deciliter of blood $(\mu \mathrm{g} / \mathrm{dl})$, have fallen dramatically (Lin-Fu, 1992). Despite this BLL reduction, approximately 900,000 children still are exposed to unhealthy levels of environmental lead (Tips, Falk, \& Jackson, 1998). This exposure comes at considerable costs to taxpayers, as Stefanak, Diorio, and Frisch (2005) estimated that it cost one Ohio county of 252,800 residents almost $\$ 500,000$ per year to screen, treat, and provide services for LE children. 
In LE children, BLLs typically peak in early childhood (around age 2 years) and decrease thereafter. Children are considerably more vulnerable to the toxic effects of lead than are adults because children ingest a higher concentration of lead than adults and also absorb more of what is ingested. Furthermore, early childhood is a period of rapid brain development, including large changes in synaptic connectivity and efficiency through myelination (Lenroot \& Giedd, 2006; Thatcher, Walker, \& Giudice, 1987), which confers additional vulnerability for the development of cognitive impairment in young LE children.

At this point, the relation between LE and IQ has been established, with an increase of from $1 \mu \mathrm{g} / \mathrm{dl}$ to $10 \mu \mathrm{g} / \mathrm{dl}$ being associated with a 3.9 to 7.4 point drop in IQ for children in the United States (Canfield, Henderson et al., 2003; Lanphear, et al., 2005), and a 1.1 to 4.6 point drop for a $10 \mu \mathrm{g} / \mathrm{dl}$ increase thereafter (Canfield, Henderson et al., 2003; Lanphear et al., 2005; Tong, Baghurst, McMichael, Sawyer, \& Mudge, 1996), with detectable intellectual deficits related to maximum blood levels less than $7.5 \mu \mathrm{g} / \mathrm{dl}$ (Lanphear et al., 2005). A recent study of 877 children in the Philippines with a mean BLL of $7.1 \mu \mathrm{g} /$ dl (Solon et al., 2008), found that the impact of low-level LE may be as high as a 2.5 to 3.3 point drop in IQ for every $1 \mu \mathrm{g} / \mathrm{dl}$ increase in BLL among disadvantaged children ages 6 months to 5 years. The relation between LE and child problem behaviors also is well understood, with an increase of one log unit of tooth lead associated with an increase of 2 points in a child's total behavior problem T-score (Bellinger, Leviton, Allred, \& Rabinowitz, 1994). LE is most consistently associated with parents' ratings of child disruptive behavior (Wasserman, Staghezza-Jaramillo, Shrout, Popovac, \& Graziano, 1998) and attention problems (Braun, Kahn, Froehlich, Auinger, \& Lanphear, 2006).

Researchers have begun to investigate the impact of low-level lead exposure (less than $10 \mathrm{ug} / \mathrm{dl}$ ) on more discrete cognitive abilities. Among children with low level LE, higher levels of blood lead (among children with low-level LE) are associated with differences in a wide range of cognitive abilities, including: visual-spatial skills (Bellinger et al., 1991; Dietrich, 2000; Dietrich, Berger, \& Succop, 1993), attention (Bellinger, Hu, Titlebaum, \& Needleman, 1994), and executive functions (Bellinger, Hu et al., 1994; Dietrich, 2000). In particular, Canfield and colleagues (Canfield, Gendle, \& Cory-Slechta, 2004) found that among 5-year-old children with an average lifetime blood lead level of $7.2 \mu \mathrm{g} / \mathrm{dl}$, higher BLLs were related to poorer performance on measures of spatial working memory, set shifting, and planning ability. The relation between LE and executive functions remains unclear, as in another study with 4-year-old low-level LE children (average $6.49 \mu \mathrm{g} / \mathrm{dl}$; Canfield, Kreher, Cornwell, \& Henderson, 2003), low-level LE was not related to performance on measures of attention, shifting, and inhibition.

Findings from studies with non-human primates are a rich resource for understanding how low-level lead exposure may relate to specific cognitive processes in young children, as complex cognition can be studied and lead exposure can be manipulated precisely without the presence of confounds of the social environmental context. To date, primate studies investigating the impact of high levels of LE have utilized paradigms that assess rule-based learning and working memory skills. Using these strategies, associations have been found between LE and learning impairment across a variety of tasks (Bushnell \& Bowman, 1979; Jadhar \& Areola, 1997; Rice \& Gilbert, 1985). On a spatial delayed alternation task, monkeys required more trials to learn the alternation rule, particularly at longer delay intervals (Rice\&Gilbert, 1990), although acquisition of discrimination reversal rules did not differ by LE status (Rice, 1985). These contradictory findings likely resulted from differences in task demands across paradigms, where impaired learning was displayed only on the more complex or difficult tasks. 
In regards to higher-order learning and working memory skills, Lilienthal, Winneke, Brockhaus, and Molik (1986) studied primates exposed both pre- and post-natally to lead (BLL of 35 and $113 \mu \mathrm{g} / \mathrm{dl}$ ) using a battery consisting of sequential discrimination tasks. Performance in the LE primates did not improve as a result of experience on similar tasks as predicted by learning theory. A task requiring monkeys to find rewards in each of six boxes in as few trials as possible (the boxes were not rebaited) was used to study working memory in monkeys exposed post-natally to lead (peak BLL of 40 and $85 \mu \mathrm{g} / \mathrm{dl}$; Levin \& Bowman, 1983). Postnatally exposed monkeys took more trials to reach the learning criterion ( 6 consecutive correct responses) than did NE controls. Taken together, LE appears to result in learning and working memory deficits as task difficulty increases.

Given the conflicting findings regarding the relation of low-level LE and executive dysfunction, the color discrimination reversal task with irrelevant form cues (Rice, 1985) is a task that might be adapted for use with young children to successfully reveal the specific cognitive substrates that are impaired after LE. On this task, monkeys learn a stimulus-response contingency. Then surface cues are altered and the impact on performance is measured. Primates with BLLs of 11 to $13 \mu \mathrm{g} / \mathrm{dl}$ responded more to irrelevant cues (e.g., always responding on one side, responding to shape instead of color) than NE controls (Rice, 1985). In particular, LE monkeys made more errors than NE monkeys when irrelevant cues were included than in the baseline condition where no cues were present. Furthermore, only when the irrelevant cues were introduced initially did the LE animals display poorer performance relative to controls (Gilbert \& Rice, 1987). Interestingly, this pattern was not observed on a non-spatial version of this task (Rice, 1985).

Therefore, this reversal paradigm with irrelevant cues was adapted here to investigate the relation between low-level LE and children's learning, distractibility, and use of problem-solving strategies. Similar tasks have been adapted successfully for use with preschoolers with LE (Canfield, Espy, \& Henderson, 2002). These spatial reversal paradigms are useful for revealing fundamental process differences by comparing performance across dependent variables (trials to first set, number of errors, number of sets), conditions (simple spatial reversal vs. addition of irrelevant cues) and groups. The addition of the irrelevant cues is intended to disrupt performance in all children, therefore, it is expected that all children will demonstrate poorer performance once irrelevant cues are added as a distracter, but group differences in the degree to which the irrelevant cues disrupt performance may reveal group differences in distractibility.

In this study, children with low-level lead exposure (LLE group) were defined as those with elevated BLL ( $\geq 5 \mu \mathrm{g} / \mathrm{dl})$ at one or more lead screenings and children with BLLs less than $5 \mu \mathrm{g} / \mathrm{dl}$ at all lead screenings comprised the very low-level lead exposure (VLLE) group. It is anticipated that children in the LLE group will demonstrate poorer performance on indices of learning (trials to first set, number of sets achieved) in the simple spatial reversal task. Because differences in learning may be due to differences in learning strategies, the types of errors children make in learning the simple reversal task also will be examined. These errors are postulated to differ between the LLE and VLLE groups, with the LLE group making more errors that suggest perseverative responding or increased persistence with an ineffective strategy. Furthermore, given the reported effects of LE on distractibility in children, preschoolers in the LLE group are hypothesized to show a greater negative impact of irrelevant cues on performance and will require even more trials to "recover" and achieve the learning criterion compared to their peers. Robust LE group-related differences are expected to be observed regardless of whether pertinent covariates are controlled statistically. 


\section{Methods}

\section{Participants}

Participants included children who received routine lead screening blood tests at the Jackson County (IL) Health Department or by their primary physician. Jackson County is a primarily rural county in southern Illinois with a population of about 60,000 . The average household income is approximately \$25,000 (United States Census Bureau, 2000). Lead screening is required for participation in many publicly funded early intervention programs and enrollment in a state-licensed school or daycare facility. Screenings also are conducted if there is an identified source of increased LE (e.g., a local building site with contaminated soil), if a family member has an elevated BLL, or if they live in a high risk area indicated by the percentage of old housing (identified by zip code).

As is general practice at the Jackson County Health Department, BLL is determined initially by a capillary fingerstick. Blood tests are performed by the Health Department licensed practical or registered nurses. Records of all lead screenings conducted in Illinois are available to the health department via a state-wide database, including those for children whose blood was screened by private pediatricians.

The Jackson County Health Department included study recruitment flyers in all mailings of children's lead screening results sent to parents of children aged 2 to 6 years who were screened at that facility. Letters also were sent to those who had been screened for lead exposure by the Health Department in the preceding 3 years. A stamped postcard was provided for parents to complete and return to the university researchers to indicate interest in study participation. This two-stage recruitment procedure was used to protect the privacy of Health Department patients.

Upon completion of informed consent procedures, a signed release of information was obtained from the parents to permit release of any lead screening results for study use. Lead exposure (LE) was assessed by peak BLL, defined as the child's highest BLL at any screening conducted. Because of cost considerations and due to the preliminary nature of the study, available lead screening data, rather than concurrent measurements, were used to index exposure. In addition, BLL data was dichotomized (above and below threshold) to increase statistical power given the sample size in this preliminary study. Low-level LE (LLE) children were defined as any child who had a peak (ever) BLL greater than, or equal to, $5 \mu \mathrm{g} / \mathrm{dl}$ and less than or equal to $10 \mu \mathrm{g} / \mathrm{dl}$. The criterion of between $5 \mu \mathrm{g} / \mathrm{dl}$ and $10 \mu \mathrm{g} / \mathrm{dl}$ (CDC criterion; Centers for Disease Control, 1991) was chosen in order to focus on the impact of sub-clinical or low-level lead exposure on specific cognitive abilities. In addition, studies of the relation between LE and brain function have found no lower limit or threshold, suggesting that even at low levels of exposure, effects on specific cognitive abilities may be seen, although this range of exposure has been investigated rarely. Very low-level LE (VLLE) children were defined as those who were screened at least once and had values less than $5 \mu \mathrm{g} / \mathrm{dl}$ on all occasions.

\section{Measures}

Spatial Reversal (SR; Kaufmann, Leckman, \& Ort, 1989). SR used a gray, wooden testing board measuring 43.0 by $20.0 \mathrm{~cm}$ with three shallow wells. The middle well was not used. The two lateral wells were $2.5 \mathrm{~cm}$ in diameter and $21.5 \mathrm{~cm}$ apart. Each well was less than $1 \mathrm{~cm}$ deep. Two beige plastic inverted coffee-type cups were used to cover the wells. In SR, af- 
ter a pre-trial where both wells were baited to determine the side of hiding for the experimental trials, the experimenter hid a reward $\left(\right.$ Cheerios ${ }^{\circledR}, M \& M s \circledR$, Froot Loops ${ }^{\circledR}$, or Rice Krispies $\left.{ }^{\circledR}\right)$ under one of the two cups out of the child's sight (under the testing table). The examiner counted aloud from 1 to 10 in an engaging manner to distract the child and reduce the use of locational cues that can improve performance (Diamond, 1988). Then, the testing board was presented to the child after the 10-second delay. The child was instructed to find the reward by lifting one cup. The child was allowed to take and eat the reward after a correct response. If the child chose an incorrect location, the examiner encouraged the child to try again on the next trial and did not allow the child to have the reward. The tray then was removed from the child's sight. The reward was hidden in the same well on each trial until the child achieved four consecutive correct responses (i.e., a set). Then, the opposite well was baited until another set of four consecutive correct responses was achieved. If the child responded incorrectly, the reward remained on the target side until a set of four consecutive correct responses was achieved. Sixteen trials were administered. Maximal performance on this task requires rule-based learning, presumably similar to theWisconsin Card Sorting Test (Heaton, Chelune, Talley, Kay, \& Curtis, 1993), and shifting of responding as rule-based contingency changes in children ages two to six (Espy, Kaufmann, McDiarmid, \& Glisky, 1999).

The variables of interest are the number of trials required before the child achieves the first set (i.e., four consecutive correct responses) and the total number of sets achieved as indices of learning. Roughly $13 \%$ of the sample attained three or more sets on this measure, indicating that only a minority of children in this sample were performing at a mastery level on this task. The number of win-shift and lose-stay errors also were examined to determine whether children's strategies varied by level of lead exposure. Win-shift errors occur when the child chooses the opposite well (i.e., shifts their response) on the trial following a correct response and lose-stay errors occur when the child chooses the same well on the trial following an incorrect response.

Spatial Reversal with Irrelevant Color Cues (SRC). This task was administered directly after SR. It was identical to SR, except that the cups used to cover the wells were painted different colors (blue and yellow). The reward continued to be hidden on the same side (as baited in the last trial of the SR task) until the rewardwas retrieved from that well for four consecutive correct trials. However, the colored cups were placed randomly across the lateral wells as a distractor, such that each colored cup covered the left or right well in a random sequence. Optimal performance required the child to ignore the color of the cup while attending to the side on which the reward was found. SRC was designed as a simulation of the tasks used by Rice in her work with primates (Rice \& Gilbert, 1985) and is intended to be more challenging than SR because the irrelevant color cues place a higher demand on attention skills and thus are intended to negatively impact performance in all preschool children.

The primary variable of interest was the number of trials required for the child to achieve the first set after the introduction of the irrelevant color cues. Because the irrelevant color cues are meant to demand greater cognitive resources that likely will result in poorer performance, the comparison of interest is whether LLE children show greater declines in performance after this manipulation as compared to VLLE children. If performance is not disrupted, the first set is achieved in only four trials. Thirty percent of children in this sample obtained the first set (i.e., four consecutive correct responses) in four trials following the introduction of the irrelevant color cues, whereas $13 \%$ failed to achieve any sets in the 16 trials administered. 
Picture Vocabulary (Woodcock \& Johnson, 1990). Because administration of a complete measure of intellectual ability is time-consuming and not directly related to study hypotheses, and because better vocabulary typically is the most correlated with overall intellectual ability (Sattler, 1992), a standardized vocabulary measure was included as an index of overall IQ. Picture Vocabulary, a subtest of theWoodcock-Johnson Psycho-Educational Battery (Woodcock \& Johnson, 1990), was applicable to children as young as 2 years. Initial items required only non-verbal pointing responses from the participant. Later items required naming pictured items or activities. The median internal consistency coefficient for this subtest was .86. Although correlations with similar measures are not available for this subtest alone, the cognitive factor with which it was associated (Comprehension Knowledge) was correlated $(r=.80)$ with the Wechsler Intelligence Scale for ChildrenRevised (WISC-R; Wechsler, 1974) Verbal Scale. Scale scores were converted to standard scores with a mean of 100 and a standard deviation of 15.

\section{Procedure}

The child was administered a battery of tasks, including the two target measures included in the current study. The order of testing was the same for all children, independent of LE group status. Testing was conducted in a quiet room, with the child sitting at a table across from the trained examiner who was blind to the child's BLL values. A pillow was provided to assist smaller children in reaching the table easily. Parents were asked to complete questionnaires concurrently with the child's assessment and lead level was obtained from the Health Department after the session. Examiners were unaware of the child's lead level, medical background, and social history at the time of the assessment. Parents were invited to remain in the testing room with their child throughout the assessment, while completing the study questionnaires in the back of the room to minimize intrusion. Assessments were videotaped for purposes of clarifying data and monitoring administration. Families received a \$25WalMart gift certificate for participation and the child received several small developmentally appropriate toys.

\section{Results}

There were 139 preschool children who participated, with a mean age at the time of testing of 3.95 years (range 2.38 to 6.05 years). The delay between lead screening and cognitive testing was, on average, 23 months (range 0 to 60 months). Ten subjects with birthweights below 4.5 pounds were excluded because of the known executive function disturbance in low birthweight children on some of the measures included in this study (e.g., Espy et al., 2002). Children were not, however, excluded on the basis of reported prenatal tobacco or alcohol exposure, as these exposures co-occur with lead exposure in sociodemographically at risk samples. Sixty-seven subjects $(48 \%)$ were male. The majority of subjects $(63 \%, N=87)$ were Caucasian, $24 \%(N=33)$ were African American, $1 \%(N=$ 2) were Hispanic, $2 \%(N=3)$ were Asian, and $8 \%(N=11)$ endorsed "other" (e.g., writing in "bi-racial"). The racial compositionwas somewhat more diverse than the larger Jackson County area from which the sample was drawn, where close to $80 \%$ of residents of Jackson County are white, $13 \%$ are African American, 3\% are Asian, and less than 3\% are Hispanic (United States Census Bureau, 2000). The mean maternal education level was approximately 14 years (range: 9 to 20 years), with an average family income $(N=111$ reporting families) of roughly $\$ 25,000$ (range: $\$ 4,000$ to $\$ 75,000$ ). 
The mean peak BLL for the entire sample was $4.2 \mu \mathrm{g} / \mathrm{dl}(S D=2.2)$. Sixty-nine children with lead screening results greater than, or equal to, $5 \mu \mathrm{g} / \mathrm{dl}$ were included (comprising the low lead exposure group; LLE), along with 70 children with BLL screening results of less than $5 \mu \mathrm{g} / \mathrm{dl}$ (very low lead exposure group; VLLE). The mean peak BLL level for the LLE group was $6.06 \mu \mathrm{g} / \mathrm{dl}(S D=1.47)$ and $2.46 \mu \mathrm{g} / \mathrm{dl}(S D=1.15)$ for the VLLE group. Preliminary power analyses, using both univariate (two group) and regression (with four predictors) design approximations $(\alpha=.05 ; \beta=.80)$ indicated that a sample consisting of approximately 45 children per group would be sufficient to detect a small to moderate effect (effect size of .30). Therefore, predicted power was adequate for the purposes here. In all analyses, $p$ values of less than .05 were interpreted as significant.

Children in the LLE and VLLE groups were compared on demographic variables (see Table 1). Results of Chi-square analyses for categorical variables indicated that the LLE and VLLE groups were comparable in the distributions of $\operatorname{sex}, \chi^{2}(1, N=138)=.113$, and race, $\chi^{2}(4, N=136)=5.95$. In addition, the exposure groups did not differ in the presence of complications at birth, $\chi^{2}(1, N=135)=.09$, whether the mother smoked during the pregnancy of the target child, $\chi^{2}(1, N=135)=1.62$, and term birth status (term vs. preterm; $\left.\chi^{2}[1, N=136]=0.08\right)$. However, the LLE and VLLE groups differed with respect to age at evaluation, $t(136)=-2.83, p=.01$, such that the LLE group mean age (4.18 years, $S D=0.93$ ) was approximately 6 months greater than that of the VLLE group (3.73 years, $S D=0.94)$. Surprisingly, given the relation between poor housing condition, LE, and low family income, average yearly family income also differed between groups, $t(109)=$ $-2.17, p=.03$, with the LLE group, on average, earning $\$ 6,700$ more per year than families in the VLLE group. Due to these premorbid group differences, age at evaluation and family income were included as covariates in all subsequent analyses.

Table I. Comparison of LLE and VLLE Group Differences-Group Means

\begin{tabular}{|c|c|c|c|c|c|c|c|}
\hline \multirow[b]{2}{*}{ Variable } & \multicolumn{3}{|c|}{ VLLE } & \multicolumn{3}{|c|}{ LLE } & \multirow[b]{2}{*}{$p$} \\
\hline & $M / n$ & $S D$ & Range & $M / n$ & $S D$ & Range & \\
\hline Age (years) & 3.74 & 0.94 & $2.4-5.8$ & 4.18 & 0.93 & $2.5-6.0$ & .01 \\
\hline $\begin{array}{l}\text { Blood Lead Levels } \\
\text { (micrograms per deciliter) }\end{array}$ & 2.46 & 1.2 & $1-4$ & 6.06 & 1.5 & $5-11$ & .00 \\
\hline Child Estimated IQ & 99.63 & 14.9 & $63-134$ & 98.59 & 14.5 & $67-129$ & ns \\
\hline Birthweight (pounds) & 7.32 & 1.06 & $4.8-9.8$ & 7.40 & 1.17 & 4.9-9.4 & ns \\
\hline Maternal Education (years) & 13.82 & 2.12 & $9-20$ & 13.85 & 2.20 & $9-19$ & ns \\
\hline Annual Family Income & 22104 & 16973 & $5600-75000$ & 28853 & 15803 & $4000-75000$ & .03 \\
\hline$\%$ male & 47 & & & 50 & & & ns \\
\hline \% Caucasian & 66 & & & 62 & & & ns \\
\hline \% African American & 24 & & & 25 & & & ns \\
\hline$\%$ other race & 10 & & & 13 & & & ns \\
\hline $\begin{array}{l}\% \text { reporting birth } \\
\text { complications }\end{array}$ & 31 & & & 34 & & & ns \\
\hline $\begin{array}{l}\% \text { reporting maternal tobacco } \\
\text { use during pregnancy }\end{array}$ & 10 & & & 18 & & & ns \\
\hline$\%$ born preterm & 10 & & & 12 & & & ns \\
\hline
\end{tabular}

VLLE = Very Low-Level Lead Exposure; LLE = Low-Level Lead Exposure; ns = not significant. 
A univariate analysis of covariance (ANCOVA) was performed comparing performance of the LLE and VLLE groups on the number of sets achieved in the SR task controlling for the effects of age and family income. Group means signified that the LLE group achieved fewer sets on the SR task, $F(1,132)=5.44, p=.02$, Cohen's $d=0.52$ (see Figure 1). The number of trials to first set on the SR task also differed as a function of lead group status, $F(1,133)=5.71, p=.02$, Cohen's $d=-0.56$ (see Figure 1). The LLE group took more trials to learn the reversal rule in the simple reversal task that is a "baseline" before the introduction of distracting cues. The LLE and VLLE groups did not differ in the number of win-shift, $F(1,133)=2.2, p=.14$, or lose-stay errors, $F(1,133)=0.47, p=.50$, on the SR task.

A univariate analysis of covariance (ANCOVA) was used to evaluate whether LE group status was related to the number of sets achieved when distracting cues were present on the SRC task while controlling for effects related to age and family income. Results indicated that the LLE and VLLE groups did not differ on the number of sets achieved in the SRC task, $F(1,130)=2.1, p=.14$.

\section{Discussion}

Children with low-level LE (LLE; mean lifetime peak BLL of $6.06 \mu \mathrm{g} / \mathrm{dl}$ ) performed differently than children with very low-level lead exposure (VLLE; mean lifetime peak BLL of $2.46 \mu \mathrm{g} / \mathrm{dl}$ ) on measures utilizing contingency-based responding. Namely, LLE children achieved fewer sets of four consecutive correct responses in the SR task than their VLLE peers. In examining the pattern of performance across tasks and groups, LLE children took more trials than VLLE children to learn the first set on the simple spatial reversal task, suggesting that LLE children showed basic deficits in learning a simple spatial contingency. Despite these differences in learning, there were no observable differences between groups in terms of learning strategy use. That is, the groups were comparable in the number of lose-stay or win-shift errors committed. In the SRC task, under conditions of higher attentional load due to distracting cues that were meant to disrupt performance of preschool children, there was no difference between LLE and VLLE children in the number of sets achieved, indicating that LE group status was not associated with greater levels of distraction when irrelevant color cues were introduced. These results indicate that preschool children with low-level LE take more trials to learn simple spatial reversal associations, and yet did not demonstrate increased distractibility under conditions of higher attentional load.
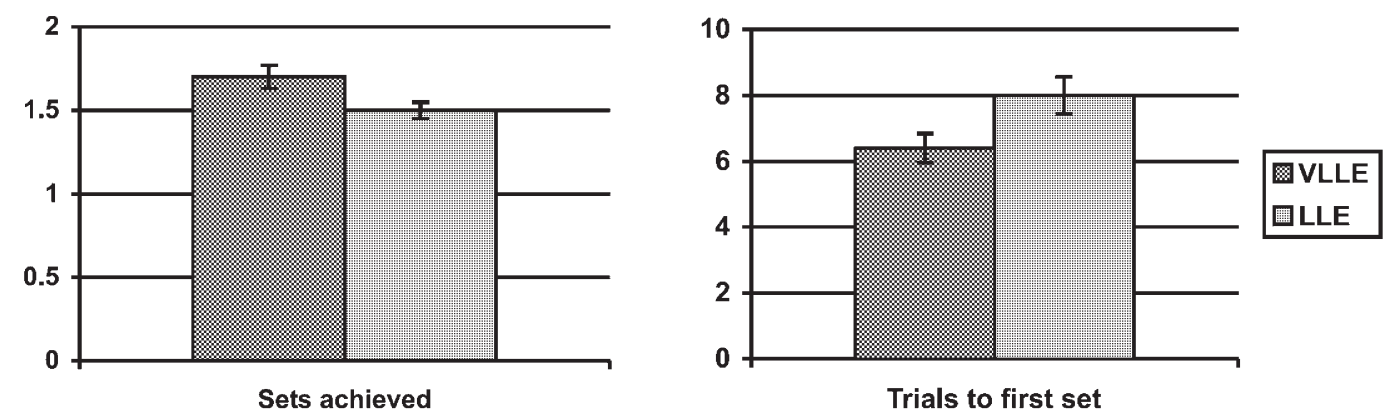

Figure I. Spatial Reversal Task performance by group (estimated marginal means). VLLE = Very Low-Level Lead Exposure; LLE = Low-level Lead Exposure 
Of note is the remarkable consistency in findings obtained here with preschool children and with non-human animals using similar procedures (Bushnell \& Bowman, 1979; Jadhar \& Areola, 1997; Rice \& Gilbert, 1990). In both studies, low-level lead exposure also was related to reductions in learning efficiency. Notably, the SR task appears sensitive to detect this effect in human preschool children. In the present study, these learning deficits were manifest in the simple spatial reversal task without the presence of irrelevant color cues, which is contrary to Gilbert and Rice's (1987) finding in lead-exposed primates where no effect on basic learning efficiency was observed. One reason for this difference may be that the primates were trained on hundreds of trials to shape responding and achieve criterion before actual testing was implemented, whereas preschool children did not receive pretraining and received only 16 trials of the simple spatial reversal task.

One possible explanation for the differences between LLE and VLLE children in association learning efficiency is that the LLE children do not change search strategies in response to negative feedback. That is, LLE children may continue to persist in using an ineffective strategy longer than the VLLE children, driven either by increased perseverative responding or by learning difficulties, both of which have been associated with higher levels of LE in prior animal research (Bushnell \& Bowman, 1979; Jadhar \& Areola, 1997; Rice \& Gilbert, 1985; 1990). In the present study, LLE children did not differ from VLLE children in the number of lose-stay or win-shift errors made, which suggests that perseveration or inadequate sensitivity to reward do not explain the observed group differences in learning efficiency. Rather, it appears that the LLE group has a fundamental deficit in learning contingency-based rules.

Results of the current study are somewhat contrary to previous findings, which have implicated perseverative responding as the basis of the higher BLL-related learning deficits. Canfield and colleagues ( 2002) observed that preschool children with low-level lead exposure exhibited fewer percent correct and fewer consecutive correct responses on a delayed spatial alternation task. However, in that study, the spatial alternation task did not include set learning, which might have reduced the sensitivity to associative learning deficits. Higher percentages of perseverative responses also were observed in 10-yearold children with higher current or recent BLL relative to those with lower BLL (Bellinger \& Stiles, 1993). The large differences in age and developmental period between this study and the present one might account for the different findings.

Children with low-level lead exposure do not appear to be more distractible than peers with less exposure. If children in the LE group were more distractible, poorer performance on the SRC task with the irrelevant cueswould be expected relative to children in the VLLE group. In fact, children in the LLE group did not attain fewer sets in the SRC task than children in the VLLE group, suggesting that low-level LE is not associated with increased distractibility in exposed preschool children. Increased distractibility has been noted in LE animals using the SR task with irrelevant cues paradigm (Gilbert \& Rice, 1987; Rice, 1985) and in older children with a history of low-level LE on a continuous performance task, but not on a cancellation or symbol coding task (Chiodo et al., 2004). The SR task appears to be sufficiently challenging for preschool children to elucidate learning differences and the presence of distracting cues did not further disadvantage those with greater LE. Given that preschool children are often exposed to bright primary colors regularly, it may be that the addition of color cues alone was not distracting enough to elucidate a performance difference. Alternatively, preschool children in general tend to be more distractible than older children; therefore, it may have been more difficult to detect a small group difference in this young sample. 
These findings may also be interpreted in light of the hierarchical competing systems model (HCSM) of executive function (Marcovitch \& Zelazo, 2009), which postulates that children's problem-solving performance is influenced by both previous experience and conscious reflection. The authors propose that initial task performance is driven more by previous experience or habit, but with increased repetition, reflection becomes more salient. The current finding that children with LLE had more difficulty learning the task contingency compared with children with VLLE, but did not differ in performance on the more difficult SRC task, may suggest that LE affects children's use of previous experience more than the development and use of reflective strategies.

In preschool children, low-level LE was associated with performance reductions on a task requiring learning of a simple reward contingency. The BLLs examined in this study were collected, on average, when the childwas about 2 years old (range 0.62 to 5.69 years of age). The relation between timing of exposure and outcome has varied among longitudinal studies. Overall, BLLs obtained around age 2 years, such as those used in this study, appear to have strongest relation to outcome (Bellinger et al., 1991; Bellinger, Stiles, \& Needleman, 1992). However, there is some discrepancy in the literature regarding whether cumulative (i.e., dentine lead levels) or current blood lead values relate best to outcome. Bergomi et al. (1989) found that dentine lead levels, but not current blood lead levels, were related to cancellation task performance in 8-year-old children. Furthermore, Bellinger and Stiles (1993) reported that cumulative lead burden may be more relevant to differences in attention performance than current BLL in school-age children because peak exposure tends to occur earlier in life and decline thereafter. In the current exploratory study, only BLL values were available.

Aspects of this study affect the generalizability of the results. The LLE and VLLE groups differed on child age and family income, which, although controlled statistically, might have influenced results. Recent research by Solon and colleagues (Solon et al., 2008) suggested a greater impact of low-level LE on IQ in a sample of disadvantaged children from the Philippines as compared with estimates of children from the United States with similar exposure. It is still an open question if social factors actually confound the relationship between LE and IQ, or if these factors modify the relationship instead (Wright, 2008). In this study, however, children with LLE performed worse despite having higher levels of family income than children with VLLE, which would presumably confer them a social advantage. Future research investigating factors that mediate or moderate the relationship between LE and cognitive function may further elucidate this relationship.

The generalizability of these results may also be impacted by the fact that the participants in this study were drawn from a convenience sample where BLLs were not drawn at universal intervals and assessments of children's abilities were not conducted concurrently with their BLL tests. The sample was drawn from a rural catchment area, which may not be comparable to urban participants involved in most extant studies. There also may be unobserved systematic environmental or genetic differences among LE children that were not captured by the distal measure of family income. Future research efforts would benefit from including more specific indexes of these proximal effects, such as the Home Observation for Measurement of the Environment (HOME; (Caldwell \& Bradley, 1984).

In the present study, preschool children with low-level LE showed poorer contingency learning on discrete measures than their peers with even lower levels of LE. More broadly, this study provides additional evidence that the investigation of specific cognitive processes using tasks adapted from neuroscience paradigms in young children ex- 
posed to lead is a useful approach. As found for other young children with a history of LE (Canfield et al., 2002) and preterm infants (Espy et al., 2002), measures such as SR and SRC discern small group differences in the component skills that comprise emergent executive control in this young age range. Therefore, these measures open possibilities to better detect how early developmental proficiencies are impacted by medical, psychological, and environmental conditions in very young children. For example, these methods might be utilized productively to characterize the impact of the home environment, parenting style, or preventive intervention on early cognitive skill development in preschoolers. Of course, there is much to be learned about the impact of sub-threshold exposures to lead and other environmental neurotoxicants on the developing nervous system in young children. The results of this exploratory study provide further evidence of the relation between low-level LE and preschool children's learning, distractibility, and strategy use, which may be extended to other age groups and contaminants.

Acknowledgments - This report is based on the doctoral dissertation of Melanie McDiarmid Nelson. This research was supported in part by an internal grant from Southern Illinois University. The first author thanks the members of her dissertation committee at Southern Illinois University Carbondale for their input into the dissertation and this resulting article, Drs. Brenda Gilbert, Mary Louise Cashel, Stephanie Dollinger, and Laura Murphy. Also appreciated is the assistance provided by the Jackson County Health Department and participating families.

\section{References}

Bellinger, D., Hu, H., Titlebaum, L., and Needleman, H. (1994). Attentional correlates of dentin and bone lead levels in adolescents. Archives of Environmental Health, 49, 98-105.

Bellinger, D., Leviton, A., Allred, E., and Rabinowitz, M. (1994). Pre- and postnatal lead exposure and behavior problems in school-aged children. Environmental Research, 66(1), 12-30.

Bellinger, D., Sloman, J., Leviton, A., Rabinowitz, M., Needleman, H. L., and Waternaux, C. (1991). Low-level lead exposure and children's cognitive function in the preschool years. Pediatrics, 87(2), 219-227.

Bellinger, D. C., and Stiles, K. M. (1993). Epidemiologic approaches to assessing the developmental toxicity of lead. Neurotoxicology, 14, 151-160.

Bellinger, D. C., Stiles, K. M., and Needleman, H. L. (1992). Low-level lead exposure, intelligence and academic achievement: A long-term follow-up study. Pediatrics, 90, 855-861.

Bergomi, M., Borella, P., Fantuzzi, G., Vivoli, G., Sturloni, N., Cavazzuti, G., Tampieri, A., and Tartoni, P. L. (1989). Relationship between lead exposure indicators and neuropsychological performance in children. Developmental Medicine and Child Neurology, 31, 181-190.

Braun, J. M., Kahn, R. S., Froehlich, T., Auinger, P., and Lanphear, B. P. (2006). Exposures to environmental toxicants and attention deficit hyperactivity disorder in U.S. children. Environmental Health Perspectives, 114(12), 1904-1909.

Bushnell, P. J., and Bowman, R. E. (1979). Persistence of impaired reversal learning in young monkeys exposed to lowlevels of dietary lead. Journal of Toxicology and Environmental Health, 5(6), 1015-1023.

Caldwell, B. M., and Bradley, R. H. (1984). Administration manual: Home observation for measurement of the environment (Revised edition). Little Rock: University of Arkansas at Little Rock. 
Canfield, R. L., Espy, K. A., and Henderson, C. R. (2002). Low-level environmental lead exposure and executive functioning in young children. Manuscript in preparation.

Canfield, R. L., Gendle, M. H., and Cory-Slechta, D. A. (2004). Impaired neuropsychological functioning in lead-exposed children. Developmental Neuropsychology, 26(1), 513-540.

Canfield, R. L., Henderson, C. R., Cory-Slechta, D. A., Cox, C., Jusko, T. A., and Lanphear, B. P. (2003). Intellectual impairment in children with blood lead concentrations below $10 \mathrm{mu}$ g per deciliter. New England Journal of Medicine, 348(16), 1517-1526.

Canfield, R. L., Kreher, D. A., Cornwell, C., and Henderson, C. R., Jr. (2003). Low-level lead exposure, executive functioning, and learning in early childhood. Child Neuropsychology, 9(1), 35-53.

Centers for Disease Control. (1991). Strategic plan for the elimination of childhood lead poisoning. Atlanta, GA: Department of Health and Human Services.

Chiodo, L. M., Jacobson, S.W., and Jacobson, J. L. (2004). Neurodevelopmental effects of postnatal lead exposure at very low levels. Neurotoxicology and Teratology, 26, 359-371.

Diamond, A. (1988). The abilities and neural mechanisms underlying A-not-B performance. Child Development, 59, 523-527.

Dietrich, K. N. (2000). Environmental neurotoxicants and psychological development. In K. O. Yeates, M. D. Ris, and D. H. Taylor (eds.), Pediatric neuropsychology: Research, theory, and practice (pp. 206-234). NewYork: The Guilford Press.

Dietrich, K. N., Berger, O. G., and Succop, P. A. (1993). Lead exposure and the motor developmental status of urban 6-year-old children in the Cincinnati Prospective Study. Pediatrics, 91, 301-307.

Espy, K. A., Kaufmann, P. M., McDiarmid, M. D., and Glisky, M. L. (1999). Executive functioning in preschool children: Performance on A-not-B and other delayed response format tasks. Brain and Cognition, 41, 178-199.

Espy, K. A., Stalets, M. M., McDiarmid, M. M., Senn, T. E., Cwik, M. F., and Hamby, A. (2002). Executive functions in preschool children born preterm: Application of cognitive neuroscience paradigms. Child Neuropsychology, 8(2), 83-92.

Gilbert, S. G., and Rice, D. C. (1987). Low-level lifetime lead exposure produces behavioral toxicity (spatial discrimination reversal) in adult monkeys. Toxicology and Applied Pharmacology, 91, 484-490.

Heaton, R. K., Chelune, G. J., Talley, J. L., Kay, G. G., and Curtis, G. (1993). Wisconsin Card Sorting Test (WCST) manual revised and expanded. Odessa, FL: Psychological Assessment Resources.

Jadhar, A. L., and Areola, O. O. (1997). Alterations in acquisition and pattern of responding in rats subchronically exposed to low levels of lead. Research Communications in Biological Psychology and Psychiatry, 22, 11-24.

Kaufmann, P. M., Leckman, J. M., and Ort, S. I. (1989). Delayed response performance in males with Fragile-X. Journal of Clinical and Experimental Neuropsychology, 12, 69.

Lanphear, B. P., Hornung, R., Khoury, J., Yolton, K., Baghurst, P., Bellinger, D., et al. (2005). Lowlevel environmental lead exposure and children's intellectual function: An international pooled analysis. Environmental Health Perspectives, 113(7), 894-899.

Lenroot, R. K., and Giedd, J. N. (2006). Brain development in children and adolescents: Insights from anatomical magnetic resonance imaging. Neuroscience and Biobehavioral Reviews, 30(6), 718-729.

Levin, E. D., and Bowman, R. E. (1983). The effect of pre- or postnatal lead exposure on Hamilton Search Task in monkeys. Neurobehavioral Toxicology and Teratology, 5, 391-394.

Lilienthal, H., Winneke, G., Brockhaus, A., and Molik, B. (1986). Pre- and postnatal lead-exposure in monkeys: Effects on activity and learning set formation. Neurobehavioral Toxicology and Teratology, 8(3), 265-272. 
Lin-Fu, J. S. (1992). Modern history of lead poisoning: A century of discovery and rediscovery. In H. Needleman (ed.), Human lead exposure (pp. 23-43). Boca Raton, FL: CRC Press.

Marcovitch, S., and Zelazo, P. D. (2009). A hierarchical competing systems model of the emergence and early development of executive function. Developmental Science, 12(1), 1-18.

Rice, D. C. (1985). Chronic low-level lead exposure from birth produces deficits in discrimination reversal in monkeys. Toxicology and Applied Pharmacology, 77, 201-210.

Rice, D. C., and Gilbert, S. G. (1985). Low lead exposure from birth produces behavioral toxicity (DRL) in monkeys. Toxicology and Applied Pharmacology, 80, 421-426.

Rice, D. C., and Gilbert, S. G. (1990). Lack of sensitive period for lead-induced behavioral impairment on a spatial delayed alternation task in monkeys. Toxicology and Applied Pharmacology, 103, 364-373.

Sattler, J. (1992). Assessment of children: Revised and updated third edition. San Diego, CA: Jerome M. Sattler, Publisher, Inc.

Solon, O., Riddell, T. J., Quimbo, S. A., Butrick, E., Aylward, G. P., Lou Bacate, M. et al. (2008). Associations between cognitive function, blood lead concentration, and nutrition among children in the central Philippines. Journal of Pediatrics, 152(2), 237-243.

Stefanak, M., Diorio, J., and Frisch, L. (2005). Cost of child lead poisoning to taxpayers in Mahoning County, Ohio. Public Health Reports, 120, 311-315.

Thatcher, R.W.,Walker, R. A., and Giudice, S. (1987). Human cerebral hemispheres develop at different rates and ages. Science, 236(4805), 1110-1113.

Tips, N. M., Falk, H., and Jackson, R. J. (1998). CDC's lead screening guidance: A systematic approach to more effective screening. [comment]. Public Health Reports, 113(1), 47-51.

Tong, S., Baghurst, P., McMichael, A., Sawyer, M., and Mudge, J. (1996). Lifetime exposure to environmental lead and children's intelligence at 11-13 years: The Port Pirie cohort study. British Medical Journal, 312(7046), 1569-1575.

United States Census Bureau. (2000). Decennial Census Data. Available from the U.S. Census Bureau website, http://factfinder.census.gov

Wasserman, G. A., Staghezza-Jaramillo, B., Shrout, P., Popovac, D., and Graziano, J. (1998). The effect of lead exposure on behavior problems in preschool children. American Journal of Public Health, 88(3), 481-486.

Wechsler, D. (1974). Wechsler Intelligence Scale for Children-Revised. San Antonio, TX: Psychological Corporation.

Woodcock, R. W., and Johnson, M. B. (1990). Woodcock-Johnson Psycho-Educational Battery-Revised. Chicago: Riverside Publishing.

Wright, R. O. (2008). Neurotoxicology: What can context teach us? Journal of Pediatrics, 152(2), 155-157. 